\title{
Mobile telecommunication standardization in Japan, China, the United States, and Europe: a comparison of regulatory and industrial regimes
}

\author{
G. van de Kaa ${ }^{1}$ - M. J. Greeven ${ }^{2}$
}

Published online: 31 August 2016

(C) The Author(s) 2016. This article is published with open access at Springerlink.com

\begin{abstract}
The process that leads to standardization in the mobile telecommunication industry has changed considerably over time. Where it was first a national process, it has gradually changed into a more global process, and the role of the government in the standardization process has changed from very influential to less influential. The role of the government now mainly consists of creating boundary conditions such as competition rules and granting licenses to operate. Finally, the number of stakeholders involved in the standardization process had increased considerably from stand-alone development of the standard to a situation in which a multitude of companies work together to develop standards. The purpose of this paper is to create insight in the changes in standardization processes in mobile telecommunication. We analyze existing theory on standardization and dominant designs and construct a framework which includes geographic setting, governmental regimes and industrial regimes. We test this framework by analyzing the standardization processes of four generations of mobile telecommunication standards in four regions (i.e., Japan, China, the US, and Europe).
\end{abstract}

Keywords Telecommunication · Standards · Regulatory regime $\cdot$ Industrial regime

M. J. Greeven

mgreeven@zju.edu.cn

G. van de Kaa

g.vandekaa@tudelft.nl

1 Delft University of Technology, Jaffalaan 5, 2600 GA Delft, The Netherlands

2 Zhejiang University, School of Management, Yuhangtang Road 866, Zijingang Campus, Hangzhou, China

\section{Introduction}

After the introduction of the telephone in 1876, the telecom industry went through a period of incremental innovation. At the end of the 1940s, the first radiotelephone was introduced in the US. This technology made it possible for mobile users in cars to connect to the fixed network. In the 1960s, a system was introduced by Bell, which brought with it some major improvements like direct calling and higher bandwidth. This system was called the improved mobile telephone system. The development of the first generation $(1 \mathrm{G})$ of mobile networks started in three continents in the same period (1980s) [1]. 1G offered new possibilities, like automatic switching and radio frequency technology, which became more important because of the increasing mobility of the workforce and the higher demand for telephones in cars. Mobile telecommunication, in fact, evolved around car usage and was not seen as a replacement for fixed telephony at the time [2]. In 1979, the first commercial cellular network was launched, and in the late 1980s, a new generation of mobile technology was introduced. This second generation $(2 \mathrm{G})$ was the first digital mobile network and offered a much higher quality of voice communication compared to the $1 \mathrm{G}$ technology. Besides the noise reduction, $2 \mathrm{G}$ technology made much better use of the available frequency spectrum, which meant networks had a higher user capacity. The development of the $3 \mathrm{G}$ started in the 1980s, under the name future public land mobile telecommunications system. The International Telecommunication Union (ITU) originally wanted to develop one single worldwide system for mobile communications, but in the end, several systems were developed under one name: International Mobile Telecommunications-2000 (IMT-2000). The $3 \mathrm{G}$ technologies provided high data rates for mobile communication, which opened the way for many new mobile services. The $4 \mathrm{G}$ technologies provided even 
higher data rates for mobile communication, enabling applications including mobile web access, and high-definition mobile TV.

In each generation and in each region, one or more standards were selected. Various scholars have studied how one or more standards are selected in markets. Economists argue that in industries that are characterized by increasing returns to adoption, single standards often emerge due to the existence of network effects $[3,4]$. Technology management scholars extend this notion by introducing factors that affect the emergence of standards and that can be directly influenced by firms [5-9]. Scholars that focus on mobile telecommunication standardization argue that firms can apply appropriability and collaboration strategies in order to achieve standard success [10]. Other scholars that focus on mobile telecommunication standardization emphasize pricing strategies, timing of entry, technological superiority, learning orientation, and brand reputation and credibility $[11,12]$. However, the influence of the standardization regime on the outcome of mobile telecommunication standardization has not been studied; this is where our contribution lies.

The question that we raise in this paper is: What is the influence of regulatory regimes and industry regimes on the process of standardization in the mobile telecommunication industry? Specifically, we investigate how standardization regimes in the mobile telecommunication industry have changed and how this has influenced the outcome of the standardization processes. We analyze the changes in standardization regimes in Japan, China, the US, and Europe for four generations of mobile telecommunication standards. First, we conduct a literature review. Based on this review, we develop a framework for the selection of mobile telecommunication standards. Using this framework, we address the differences in the standardization regimes, with the aim to explain the impact of these different regimes on the outcome of the standardization processes. Finally, we discuss the results, the limitations and the theoretical and practical implications of our study, and give recommendations for further research.

\section{Literature study}

This paper focuses on the influence of the regulator on the outcome of battles between compatibility standards for telecommunication. David and Steinmueller [13] define compatibility or interface standards as “.... standards [that] assure the user that a component or sub-system can successfully be incorporated, and be "inter-operable" with other constituents of a larger system of closely specified inputs and outputs".

\subsection{Factors for standard dominance}

Different factors can influence the outcome of standards battles [9]. In the literature, a distinction is made between the firm and the environmental level [7]. Firm level factors include strategies companies can follow and assets that companies possess. Examples of strategies described in the literature are building an early lead [14], product pre-announcements [15], pre-emption and expectations management [16], attracting suppliers of complements [14,17], establishing a diverse industry network [18], entry timing [7], pricing strategies like price commitment and penetration pricing $[14,16,19]$, licensing strategies like second sourcing [20,21], and operational supremacy [22]. Technological superiority was often thought to be the most important asset for a standard to become dominant, but there are numerous examples of standards that became dominant without being technologically superior [23]. Other examples of assets are installed base $[4,15]$, the ability to innovate, the efficiency of production [16] and brand name and reputation [16]. One important asset that has played a large role in the telecommunication industry is the possession of intellectual property rights (IPRs) $[10,16]$. Companies can develop technologies and choose to keep the specifications proprietary, make them publicly available, or make an agreement with other actors that the IPRs will be made available on reasonable and non discriminatory (RAND) terms. Recently, scholars have also attempted to determine weights for factors for standard dominance [24-26].

Environmental factors can also play a large role. Examples of environmental factors are network externalities, bandwagon effects, switching costs [3,4,14,19,27-29], regulations [7], the geographic setting in which a dominant design emerges [30], the number of actors, and degree of competition versus cooperation [7]. Network effects are especially important in telecommunication. These effects signify that the value of a product in which a standard is implemented increases if the number of users adopting that product increases. In this paper, the emphasis lies on a specific environmental factor: regulation. This signifies the regulatory regimes, which are involved in mobile telecommunication standardization.

\subsection{Standardization processes}

The literature distinguishes between official or de jure standardization and standardization by the market or de facto standardization. David and Greenstein [31] state that standard agreements by voluntary standards-writing organizations and mandated standards promulgated by legislative bodies or by order of governmental agencies with regulatory authority are de jure ways of standardization. On the other hand, de facto standards are outcomes of market-mediated 
processes. Farrell and Saloner [28] introduced a hybrid form with elements of negotiation and market action. Recently a fourth form, the network form, has been discussed in which standards are initially developed in committees and later introduced in the market [32].

In this paper, de facto and de jure will be taken as the two extremes in standard development processes. The terms will be used to describe pure forms of standardization: solely by participants through market mechanisms, or solely by governments mandating standards. A wide range of standardization types are possible. For example, governments can accommodate in standardization processes by bringing actors together to cooperate, or they can limit their influence by creating boundary conditions. Companies can develop a technology on their own or work together with other actors in the industry through consortia or standard development organizations. We investigate the regimes in four regions and consider the shift of standardization regimes on the line between de facto and de jure standardization.

Standardization literature focuses on the development and sponsoring of standards by actors involved in the standardization process. Standards can be developed in different ways. They can be developed by authorities, by a company, or by consortia of actors [33]. Actors can also establish a standard organizations (SOs) or join an existing SO. There are many varieties of SOs, such as consortia (alliances of companies and/or other organizations), formal standardization organizations at the international level [such as the ITU, the International Organization for Standardization (ISO), and the International Electrotechnical Commission], formal standardization organizations at the regional level [such as the European Telecommunications Standardization Institute (ETSI), the European Committee for Electrotechnical Standardization (CENELEC), and the European Committee for Standardization (CEN)] and formal standardization organizations at the national level [such as the American National Standards Institute (ANSI) and the German Institute for Standardization (DIN)]. Other SOs include sectoral standardization organizations (which unite parties in a certain branch of business such as trade associations [such as the Telecommunications Industry Association (TIA) and proof of technology consortia], governmental standardization organizations (governmental agencies other than a formal standardization organization), and professional standardization organizations (which unite parties with a common field of technical expertise such as the Institute of Electrical and Electronics Engineers, IEEE) [34,35].

Actors can be involved in SOs in a variety of ways. In case of formal standardization, they can be involved both at the national and at the international level. They can be involved because of their expertise, or on behalf of an organization. This could be their employer, another organization (e.g., a business organization), or a country. In terms of stakeholder involvement, many consortia resemble formal standardization organizations [36], but they mostly lack the combination of national and international level. A detailed discussion on standardization approaches in SOs in general is provided in $[30,35,37]$.The following provides a comparison of the standardization approaches by TIA, ETSI and ITU (see Table 1 for an overview).

\subsection{A comparison of the standardization approaches deployed by TIA, ETSI and ITU}

The information presented in this section originates from various documents found on the organizations' websites [3840].

First, there is a difference in the institutional level at which these organizations operate and the type of members that are involved. While the TIA is a US trade association in which primarily US companies are active, the ETSI is a regional SO that primarily consists of European member states. ${ }^{1}$ The ITU-T is a United Nations specialized agency that is concerned with international standardization and it mainly consists of UN governments. The TIA is officially recognized as a standards developer by the ANSI and the ETSI is recognized as one of the three official European SOs. In each of the three standardization organizations members have to pay annual fees in order to be a member of the organization.

Second, the ETSI develops European standards and the ITU develop international recommendations that when adopted as part of a national law become mandatory. In the case of China, ITU plays an important role, where China is a formal member and active in proposing standards. For instance, in the case of LTE-Advanced standards, China successfully proposed the TD-LTE standard with the ITU. However, the TIA develops national standards that apply for the products that are manufactured by TIA members and these standards may eventually become national ANSI standards and these ANSI standards in turn may become international (ISO) standards.

Third, the actual process of standardization is different per organization. At the TIA the process of standardization starts with a technical proposal that may be made in a TIA committee or subcommittee. The proposal will be evaluated by TIA staff, and, when approved, the committee or subcommittee within which the proposal was made will be involved in drafting and reviewing the standard. When the standard is finished the standard may be approved as a TIA standard at a separate meeting. At that meeting more than half of the

\footnotetext{
${ }^{1}$ ETSI was originally established to develop European standards but increasingly is moving towards the development of other types of standards including international standards and companies, universities and research institutes from a diverse range of countries inside and outside of Europe have joined. However, the focus in this paper lies on ETSI as a developer of European standards.
} 
Table 1 A comparison of the standardization approaches developed by TIA, ETSI and ITU

\begin{tabular}{|c|c|c|c|}
\hline & TIA & ETSI & ITU-T \\
\hline Type of organization & Trade association & Regional standards organization & $\begin{array}{l}\text { International standards } \\
\text { organization }\end{array}$ \\
\hline Type of members & (US) companies & $\begin{array}{l}\text { EU national standards } \\
\text { organizations, companies, } \\
\text { universities and research } \\
\text { institutes }\end{array}$ & $\begin{array}{l}\text { UN member states, firms, and } \\
\text { academia }\end{array}$ \\
\hline Organizational level & National & European & International \\
\hline Type of standards & Telecommunications & Telecommunications & Telecommunications \\
\hline Voting process & $\begin{array}{l}\text { The standard is approved if at least } \\
50 \% \text { of the votes are cast in } \\
\text { favour }\end{array}$ & $\begin{array}{l}\text { The standard is approved if at least } \\
61 \% \text { of the votes are cast in } \\
\text { favour }\end{array}$ & $\begin{array}{l}\text { The standard is approved if at least } \\
50 \% \text { of the votes are cast in } \\
\text { favour }\end{array}$ \\
\hline Participation in committees & One voting member per company & One vote per European country & One vote per UN member state \\
\hline Openness & $\begin{array}{l}\text { Every member has to pay fees for } \\
\text { participating }\end{array}$ & $\begin{array}{l}\text { Every member has to pay fees for } \\
\text { participating }\end{array}$ & $\begin{array}{l}\text { Every member has to pay fees for } \\
\text { participating }\end{array}$ \\
\hline
\end{tabular}

members should be present and the standard will be approved when at least $50 \%$ of the votes are cast in favour. One representative per company is allowed to participate during the process of voting. After the standard is approved it will be published and subsequently the maintenance stage starts.

The process of standard development within ETSI is comparable to the process at TIA but an additional step (public enquiry) is added. First, a proposal for a new standard may be submitted by either an ETSI member, the European Commission or the European Free Trade Asociation. The proposal needs to be endorsed by at least four ETSI members. Next, the actual drafting of the standard occurs in technical committees that are made up of member representatives and led by a 'rapporteur'. After the approval of the standard within the technical committee the standard is made available to each national SO in Europe. Next, the public enquiry is carried out. This consists of gathering the votes of each national SOs in Europe. If the vote is successful the standard is published. During the public enquiry stage any comments received will be taken into account in the standard and if this will lead to significant changes in the standard another round of voting may occur. Votes are successful if at least $71 \%$ of the weighted votes are cast in favour. The votes of nations are weighted as agreed upon by the general assembly of ETSI. The last steps involved are publishing the standard and the maintenance of the standard.

Every ICT organizations or academic institute may become a member of the ITU and they may identify an issue for ICT standardization. That issue is evaluated by a study group and, if approved, it is allocated to a working party which starts with drafting a new recommendation. When the recommendation is mature enough it will be evaluated by the working party and the study group. During this stage input may be given by both UN member states and sector members. At a certain stage the recommendation may be given consent and it may then move to the approval stage. Approval is based upon a voting process whereby each UN member state may cast one vote. The draft is approved if a majority is in favour meaning that more than half of the delegations present is in favour. For such a decision to be made more than half of the voting members must be present at the meeting. Before actual approval commences a period of 4 weeks begins in which the recommendation is evaluated and reviewed by UN member states and sector members. If no comments are received the draft may be approved. However, if substantial comments are received a period of 3 weeks commences in which the draft is reviewed for a second time. If no significant comments are received the draft is approved. If comments are received during these 3 weeks the draft will be discussed in a plenary meeting of the study group and possibly approved.

Summarizing, these three standardization organizations have different operating mandates for different regions. Moreover, ETSI and ITU develop standards recommendations that may become part of national laws, while TIA is mostly focused on developing and enforcing standards for members of the TIA in the USA. Lastly, the process of standardization is different in the three organizations.

\section{Framework}

We chose two factors, the influence of the regulatory (governmental) regime and the industrial regime on standardization, to describe the start of the development of a standard (point A in the framework) and the process of the development of dominant telecommunication industry standards (B). Research has shown that institutions influence the standardization process [41]. Other studies have highlighted the importance of industry and trade associations within the standardization process [42]. Recently Van de Kaa et al. [43] opened 


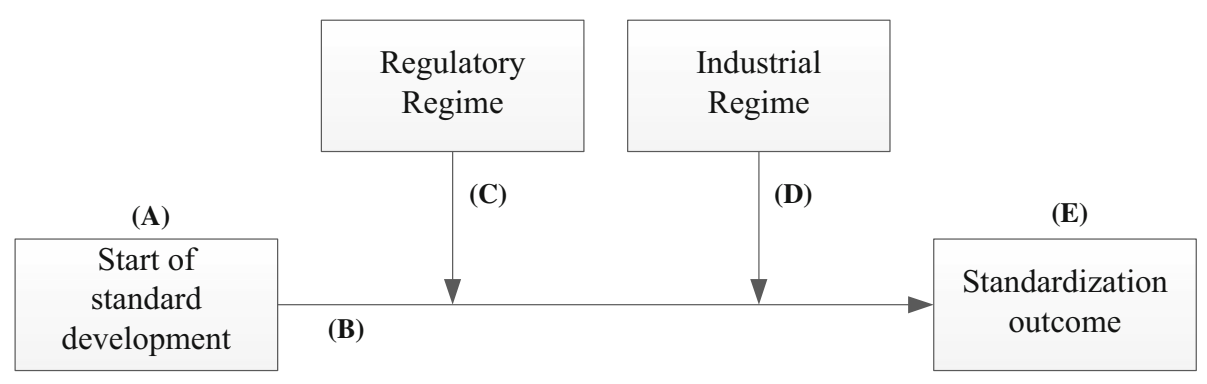

Fig. 1 Research framework

up the black box of the Chinese government showing that the role of the government in standardization is dynamic and complex. Governments worldwide have always had much influence on the telecommunication industry (C). In many countries, telecommunication operators used to be state owned monopolies, which controlled the market and ensured that telecommunication were available to the general public. But the role of governments has changed in the last few decades. Worldwide, governments initiated reforms in the telecommunication industry, which are often called the deregulation, liberalization, and privatization of telecommunication. This changed the industry; competition was introduced and the market also became more internationally orientated. Standardization processes also changed. Whereas before governments had great influence on market actors like equipment manufacturers, now the market consists of multiple actors, which all can participate in the standardization process (D). The increase of actors in the value chain had its impact on the industrial influence on standardization processes. We use the factors mentioned earlier to classify the type of standardization in a standard development process, and how they influence the standardization outcome (E). This will be done using the model presented in Fig. 1.

\section{Methodology}

We investigate 16 cases of standardization processes for telecommunication. The cases were chosen on a geographic basis: Japan, China, the US, and Europe. We chose these regions because they can be seen as the regions where mobile telecommunication was developed. We examine the development of four generations of mobile telecommunication in each region. The term generation $(\mathrm{G})$, is used to depict mobile technologies with certain characteristics, in which each subsequent $\mathrm{G}$ is an improvement of the previous one. $1 \mathrm{G}$ is used to define analogue mobile technology. $2 \mathrm{G}$ made mobile telecommunication digital, $3 \mathrm{G}$ is digital technology capable of higher data rates, and $4 \mathrm{G}$ currently enables the highest possible data rate. To investigate the changing standardization processes in the mobile telecommunication industry, we compare the different standardization regimes in the 16 situations. First, we examine the standardization regimes of mobile telecommunication per region and then discuss the four Gs of mobile technology. Next, we compare the four regions and the four Gs and present the results of our analysis.

\section{Cases}

\subsection{Japan}

The Japanese standardization development is characterized by a shift from high governmental influence in $1 \mathrm{G}$ and $2 \mathrm{G}$, to a more open stance of creating boundary conditions by the government in $3 \mathrm{G}$ and finally, no governmental involvement in $4 \mathrm{G}$.

The government has had a major influence through the incumbent operator and market leader, Nippon Telegraph and Telephone Corporation (NTT). The 1G NTT system was developed by NTT and mandated by the government. Also, a Japanese version of the US AMPS system was used [Japan total access communications system (TACS) standard]. The 2G PDC and PHS (short range) systems were also mainly developed by the NTT [1], although this time foreign companies were allowed in the development. A shift came between $2 \mathrm{G}$ and $3 \mathrm{G}$. Until then the proprietary technologies developed in Japan had a low level of diffusion. Mobile telecom had become a global industry, and the Japanese contacted European firms to work together on the development of a $3 \mathrm{G}$ system. ARIB and TTC, two standardization organizations, were responsible for the coordination of the standardization efforts, in which multiple companies could participate. Again, the NTT proposal was chosen. The government did not mandate a $3 \mathrm{G}$ standard, which resulted in the use of both the W-code division multiple access (W-CDMA) and CDMA2000 standard. The 3G partnership project (3GPP) forum adopted W-CDMA for further development.

Although the Japanese government was not involved in $4 \mathrm{G}$ mobile telecommunication standardization, Japanese companies (such as Fujitsu) were active in worldwide interoperability for microwave access (WiMAX) standardization and ARIB was also heavily involved in the 3GPP. Table 2 summarizes the standardization regimes in Japan. 
Table 2 Standardization regimes in Japan

\begin{tabular}{llll}
\hline & Government roles & Industry roles & Sources \\
\hline $1 \mathrm{G}$ & Mandate & Stand-alone & {$[12]$} \\
$2 \mathrm{G}$ & Mandate & Stand-alone & {$[1,12,58]$} \\
$3 \mathrm{G}$ & Boundary conditions & SDO, forum & {$[12,53,58]$} \\
$4 \mathrm{G}$ & No involvement & SDO, forum & {$[54]$} \\
\hline
\end{tabular}

\subsection{China}

The Chinese standardization development is characterized by a shift from depending solely on international standards to independently developing its own standard, as well as a shift from mandating solely by the government to collaborating with industrial organizations. As Ms. Chen from a local technology consultancy explained: "Technology development and standardization are aimed at promoting indigenous technology and protecting the interests of domestic companies, institutions and government. Nevertheless, it should hardly be considered politically motivated but rather technology and economically motivated."

It can be concluded that China played no role in the development of $1 \mathrm{G}$ and $2 \mathrm{G}$ technologies [44]. The $1 \mathrm{G}$ system TACS (UK origin), was introduced and mandated by the government. The 2G GSM and CDMA systems were both gradually established in China after China Unicom was founded in 1994. In both cases there was no role for local industry partners.

As Mr. Huang from Zhejiang University Information and Computing Science Department stated: "Later due to a rapid increase in demand, the telecom industry in China was able to leapfrog." A shift occurred between the second and 3G. Until then, with the advancement of modern technology, China had equipped itself with the ability to develop its own standard. Thus, the Chinese Academy of Telecommunication Technology, Datang Telecom, and Siemens AG started to develop TD-SCDMA in an attempt to avoid dependence on western technology. As Mr. Li from Zhejiang University Information and Computing Science Department said: "In 2000, ITU announced 3G international standards which included WCDMA from Europe, CDMA2000 from US, and TD-SCDMA which was domestically developed by China." In the meantime, the TD-SCDMA Industry Alliance was founded in October 2002 to support the development of TD-SCDMA. It consisted of members of both domestic and foreign companies including Huawei, ZTE, Datang, Lenovo, TCL, Haier, and ZCTT. As Mr. Huang (ibid) said: "In 2008, China launched the telecom system reform which changed dramatically the interest pattern of the three service providers, telecom equipment suppliers like Huawei and ZTE, and application and solution suppliers." After that, TDSCDMA was assigned to China Mobile by the Ministry of
Industry and Information Technology. In the meantime, the other two international standards: CDMA2000 and WCDMA were also assigned to the other two phone carriers, China Unicom and China Telecom, respectively [45]. Interestingly, this $3 \mathrm{G}$ standard has gained significant market share within China, but has not been successfully exported, partly due to technological disadvantages.

During the process of internationalization of its own developed standard, Chinese companies like Huawei and ZTE gradually became global market leaders in equipment manufacturing, including technology and standards setting. In 2005, China embarked on the development of $4 \mathrm{G}$ with the common effort of both government and industry. Huawei and ZTE are currently successfully rolling out $4 \mathrm{G}$ equipment supported by the key telecommunication service providers in China, China Mobile, China Telecom, and China Unicom.

Mr. Huang (ibid) described the transition from $3 \mathrm{G}$ to $4 \mathrm{G}$ development as follows: "By then, the whole TD industry chain consisting of the government, the operator, and equipment suppliers had been sophisticated enough. In order to update from $3 \mathrm{G}$ to $4 \mathrm{G}$ with the lowest cost and highest efficiency, a part of TD-SCDMA technology and a part of LTE TDD technology were combined to form the TDLTE." Currently, China's 12th Five Year Plan and MLP [National Medium- and Long-term Plan for the Development of Science and Technology (2006-2020)], encourages the development of indigenous innovation and the creation of framework conditions for technological development, including standardization.

Overall, the Chinese government and industry alliances both played a significant role in the $3 \mathrm{G}$ and $4 \mathrm{G}$ telecom development. The government has provided flexible policies and financial support to promote the development of its own standard, aiming to avoid dependence on western technology [46]. And the alliances push related companies to form the development chain based on the companies' own technological advantages [47]. Meanwhile, even though the government strongly supports its own standard, it allows the development of international standards in China and assigns the operating authority to various carriers. There is no doubt that with the advancement of technology, Chinese own-developed standards are making progress in both technology and service aspects, leading to a higher satisfaction rate among its users [48]. In the long run, we could conclude that Chi-

Table 3 Standardization regimes in China

\begin{tabular}{llll}
\hline & Government roles & Industry roles & Sources \\
\hline $1 G$ & Mandate & No role & {$[44,47]$} \\
$2 \mathrm{G}$ & Mandate & No role & {$[44,47]$} \\
$3 \mathrm{G}$ & Mandate, accommodate & SDO, forum & {$[45,46]$} \\
$4 \mathrm{G}$ & Mandate, accommodate & SDO, forum & {$[46,54]$} \\
\hline
\end{tabular}


Table 4 Standardization regimes in the US

\begin{tabular}{llll}
\hline & Government roles & Industry roles & Sources \\
\hline $1 G$ & Mandate & Stand-alone & {$[12,58]$} \\
$2 \mathrm{G}$ & No involvement & Consortia, stand-alone & {$[12,58]$} \\
$3 \mathrm{G}$ & No involvement & SDO, consortium, forum & {$[12,58]$} \\
$4 \mathrm{G}$ & No involvement & SDO, forum & {$[54]$} \\
\hline
\end{tabular}

nese own-developed standards will have a dominant market share within China. Table 3 summarizes the standardization regimes in China.

\section{$5.3 \mathrm{US}$}

The US standardization development is characterized by a shift from the government mandating a standard in the $1 \mathrm{G}$ to a more distant stance in subsequent Gs, and a shift in industry from stand-alone development to partnerships in development. While the government relied on the market while developing the successful $2 \mathrm{G}$ and $3 \mathrm{G}$ standards, unwittingly it had a major impact on the competitiveness of the US mobile telecommunication industry, because of the laborious spectrum allocation and licensing policies. $1 \mathrm{G}$ was developed mainly by AT\&T/Bell and Motorola before it was chosen as a standard by the Federal Communications Commission (FCC) and made publicly available. 2G D-AMPS was developed by the Cellular Telephone Industries Association. The other major US 2G standard, CDMA, was pioneered by Qualcomm and later sponsored by other large industry participants. The $3 \mathrm{G}$ standard development came as a reaction to the cooperation of European and Japanese firms, and was the reason for cooperation between Motorola, Qualcomm, Lucent, and Northern Telecom, which all had great market shares in the CdmaOne market [12]. Qualcomm has played an important role in telecommunication standardization because of its closed licensing policies. $3 \mathrm{G}$ systems worldwide were based on Qualcomm's CDMA technology, of which the company holds many essential patents, which it did not want to license to other companies. The other important party in the IPR dispute was Ericsson, which also claimed to hold many essential patents. The issue was resolved by agreeing to cross-license their essential IPRs. In addition to the CDMA2000 standard, the UWC-136 (or EDGE) standard was developed by the UWCC. CDMA2000 was further developed by the 3GPP2 forum, while UWC-136 was adopted by the 3GPP2 forum. In $4 \mathrm{G}$ mobile telecommunication standardization, the role of the US was also apparent as many US companies participated heavily in the WiMAX forum, including Agilent Technologies, Inc. and Hughes Communications, Inc. The US was also involved in the 3GPP through the Alliance for Telecommunications Industry Solutions. Table 4 summarizes the standardization regimes in the US.

\subsection{Europe}

European standardization efforts shifted from highly diffuse processes in $1 \mathrm{G}$, to a collaborative effort in $2 \mathrm{G}, 3 \mathrm{G}$ and $4 \mathrm{G}$ standardization. During the $1 \mathrm{G}$, many countries developed their own standard, which led to incompatible technologies. The Nordic countries worked together to create a compatible system which resulted in the Nordic mobile telephone (NMT) standard. This was initiated by the governments of these countries, which agreed to cooperate, and allowed the countries' operators and manufacturers to develop a panScandinavian system. The UK developed the TACS [1]. For the development of the $2 \mathrm{G}$ system, GSM, the European Union set up The ETSI in which governments, operators, manufacturers, and other actors worked together to create one European standard. This de jure way of standardization resulted in the most successful standard so far. The GSM project was almost jeopardized because of IPR issues [10]. Motorola held many essential patents for the technology, and did not agree to share these patents with other manufacturers. Later, a declaration was signed by the operators, which states that manufacturers should support the GSM community and offer their patents on RAND basis. The standard was mandated by European law, which required the use of European standards by member states in public procurement [49]. ETSI took a leading role in $3 \mathrm{G}$ and cooperated with Japanese companies to build a system based on W-CDMA technology. This standard, however, could not be mandated because of international trade law.

The W-CDMA standard was further developed by the $3 \mathrm{GPP} 2$ forum. Europe was active in both the WiMAX forum (through e.g., Nokia and Siemens) and in the 3GPP (ETSI). Table 5 summarizes the standardization regimes in Europe.

\section{$5.51 \mathrm{G}$}

The governmental regimes in all four regions in $1 \mathrm{G}$ standards were quite similar. This is because the telecommunication industry was dominated by monopolies, which were often state owned during $1 \mathrm{G}$ standard development. The governments had great influence over the market and over the choice of certain standards. That is why standards were mandated by governments in every region. Only in Europe, with the NMT standard, the governments played an accommodating role, by agreeing to cooperate in the development of a pan-Nordic system, but left the standardization to the public telephone operators and manufacturers such as Ericsson and, later, Nokia [1,50]. In Japan, the ministry was in charge of the telecommunication industry through NTT, which was the incumbent operator, but also had its own research facilities. In the US, the FCC decided upon one technology as the national standard. 
Table 5 Standardization regimes in Europe

\begin{tabular}{llll}
\hline & Government roles & Industry roles & Sources \\
\hline $1 \mathrm{G}$ & Mandate, accommodate & Stand-alone, consortium & {$[1,12,50,58]$} \\
$2 \mathrm{G}$ & Mandate & SDO & {$[10,12,58]$} \\
$3 \mathrm{G}$ & Boundary conditions & SDO, forum & {$[12,53,58]$} \\
$4 \mathrm{G}$ & No involvement & SDO, forum & {$[54]$} \\
\hline
\end{tabular}

Only a few industrial participants were dominant in standardization. These were NTT and the 'NTT Family' firms in Japan, AT\&T/Bell and Motorola in the US. In Europe, with systems other than NMT, national firms such as Siemens in Germany, Italtel and Telletra in Italy, and Matra in France, were involved in the development of the systems. Foreign companies were also involved in the NMT development.

China did not have its own $1 \mathrm{G}$ standard. It only started to actively develop its own telecom standard in the $3 \mathrm{G}$ times, with its TD-SCDMA standard [44]. However, Chinese did import $1 \mathrm{G}$ technology which is TACS standard from the UK and applied it in the country for 14 years, i.e., from 1987 to 2001. Even though only very few people could afford the expensive equipment and service in the $1 \mathrm{G}$ era in China, the number of $1 \mathrm{G}$ users still once reached over 6 million [51].

$1 \mathrm{G}$ standardization was thus handled in a largely de jure way. This, however, changed when the incumbents lost their absolute power due to liberalization efforts which had already begun during the deployment of the $1 \mathrm{G}$ system, or were about to begin somewhat after this. This can be seen in $2 \mathrm{G}$ standardization.

\section{$5.62 G$}

$2 \mathrm{G}$ standardization shows a diversified picture of standardization processes. The Japanese government, which still had a large influence through NTT, mandated a standard resembling the $1 \mathrm{G}$ process. This policy resulted in a proprietary system, which was widely adopted in Japan, but scarcely outside Japan. In the US, the role of the government changed from mandating a single standard to letting the market decide on the development of a standard. This resulted in the presence of multiple standards. Again, the allocation of licenses took a long time and many companies applied for licenses because the government allocated them through a 'lottery'. Among them were many companies, which had no intention or resources whatsoever to deploy a mobile telecommunication network, but made large profits by selling licenses to companies that did. In Europe, standardization efforts were carried out by one organization, ETSI, which was established to create one European standard [10]. The standard was mandated because of requirements negotiated by the EU member states. There are also notable differences in the industrial environment across the regions. In Japan, the NTT still had the most power, and in the US, Qualcomm developed proprietary technology. Also, private companies, which had supported the $1 \mathrm{G}$ standard, joined forces to develop a digital version of the $1 \mathrm{G}$ standard. In Europe, operators and equipment manufacturers reached consensus through ETSI.

Thus in the $1 \mathrm{G}$, standardization was a de jure process in every region, whereas in the $2 \mathrm{G}$ a de facto standardization process took place in the US. In Japan, the process can still be characterized as de jure standardization, although some competition was introduced. In Europe, a noticeable shift occurred from purely de jure standardization to a process where industry participants became more influential in the process. In China, again we see a de jure process, where there was no role for local industry, and a strong government mandate for GSM, however, IS-95 and CDMA were also allowed. Nevertheless, China established GSM networks in 1995, and by 2000 close to 50 million subscribers were using GSM [52]. While it was thought that standardization through an official committee would be too cumbersome and would take too much time, the GSM standard became the most successful of all $2 \mathrm{G}$ standards. This result influenced the way standards were developed in $3 \mathrm{G}$ standardization.

\section{$5.73 G$}

3G standard development was mainly shaped by the globalization of the telecommunication industry. The ITU took the first steps in trying to create one worldwide standard to accommodate worldwide roaming and large economies of scale. In the regions, SDOs took the role of representing industry, and in the US, a consortium was established to do so. Government involvement was further changed to creating boundary conditions like spectrum allocation and formulating competition law. No single standards were mandated in any of the regions, in accordance with international trade agreements. Industry in Japan and Europe participated in regional standardization bodies, and also worked together on the W-CDMA standard. The US once again relied on the market process. The industry participants' proposal for CDMA2000 was a late reaction to the proposal from Japan and Europe, which again put US companies behind in standardization efforts. Another important technology in the 
IMT-2000 family of technologies is TD-SCDMA, which is a standard developed in China. W-CDMA was most successful [53].

The SDOs and consortia which issued their proposals for $3 \mathrm{G}$ systems later joined in two forums; the $3 \mathrm{GPP}(\mathrm{W}$ CDMA, TD-SCDMA, EDGE) and 3GPP2 (UWC-136 and CDMA2000) to further develop the technologies [1]. In these forums, other industry representatives could also take part in further developing the standards. Standardization for $3 \mathrm{G}$ standards thus became a process whereby standards were proposed by official bodies in the different regions and, after approval, taken over by global organizations for further development.

\section{$5.84 \mathrm{G}$}

4G standardization is characterized by further globalization and the increasing role of formal SOs. Development of $4 \mathrm{G}$ technology can be traced back as early as 1999 when the IEEE standards board established a working group to develop standards for wireless metropolitan area networks. The first version of IEEE 802.16 was developed in 2001 and was eventually developed into IEEE $802.16 \mathrm{~m}$ or WirelessMANAdvanced. The WiMAX forum industry alliance promotes and certifies compatibility and interoperability of products based on IEEE 802.16 standards. The 3GPP developed the LTE standard, which was first proposed in 2004 and which is an upgrade to the GSM and CDMA2000 networks.

In 2008, the ITU issued a set of requirements, which $4 \mathrm{G}$ standards should comply with. This set of requirements are referred to as the IMT-Advanced project [54]. To ensure that these requirements were met, the 3GPP developed the LTE-Advanced standard. Furthermore, IEEE developed the IEEE $802.16 \mathrm{~m}$ standard. China's MIIT submitted its TDLTE-Advanced specification [54]. Each of these standards met the requirements of the IMT-Advanced standard, making them true $4 \mathrm{G}$ standards.

Both the LTE-Advanced standard and the IEEE $802.16 \mathrm{~m}$ standard were developed by formal SOs in which Europe, the USA, and Japan were heavily involved. However, interestingly, new upcoming countries such as China, South Korea, India, and Malaysia have gradually become more involved. In fact, the 3GPP is now a collaboration between groups of telecommunication associations from Japan, the USA, China, Europe, Korea, and India. Besides, China has developed its own TD-LTE-Advanced specification, which is the result of a joint collaboration between industry and government.

Standardization for $4 \mathrm{G}$ standards thus became a process whereby standards were developed partly by official bodies (IEEE), partly by forums (3GPP), and partly by governmental agencies (MIIT).
Table 6 Differences in standardization regimes in the four regions and the four generations

\begin{tabular}{lll}
\hline & Government roles & Industry roles \\
\hline 1G & & \\
Japan & Mandate & Stand-alone \\
China & Mandate & No role \\
US & Mandate & Stand-alone \\
Europe & Mandate, accommodate & Stand-alone, consortium \\
2G & & \\
Japan & Mandate & Stand-alone \\
China & Mandate & No role \\
US & No involvement & Consortia, stand-alone \\
Europe & Mandate & SDO \\
3G & & \\
Japan & Boundary conditions & SDO, forum \\
China & Mandate, accommodate & SDO, forum \\
US & No involvement & SDO, consortium, forum \\
Europe & Boundary conditions & SDO, forum \\
4G & & \\
Japan & No involvement & SDO, forum \\
China & Mandate, accommodate & SDO, forum \\
US & No involvement & SDO, forum \\
Europe & Boundary conditions & SDO, forum \\
\hline
\end{tabular}

\section{Discussion and conclusion}

When looking at the cross-case study analysis (Table 6), we can observe a general trend from stand-alone development, where national champions played an important role, to development with the participation of a large number of different kinds of companies. However, there are still a few very large equipment manufacturers, which have participated in standardization efforts through the Gs, which have a large stake in the process like Motorola, Qualcomm, Ericsson, Nokia, and NTT. However, the number of participators influencing the standardization process has grown enormously with the convergence of mobile telecommunication and the Internet.

The role of the government worldwide has shifted from a dominant role in the standardization process in the early years of mobile telecommunication to a role of ensuring fair competition, granting licenses and making and adoption rules, which consider the interest of the general public. National agencies have been established to monitor industry. International trade agreements ensure that standards, which could favor certain companies and hinder competition in the form of trade barriers cannot be mandated.

In general, we can conclude that on the line between de facto and de jure standardization, the process has moved to a point where the basis for new standards is devel- 
oped in an official way and that industry then takes over (essentially a form of network governance [32]). This is done in an organized way, through consortia or forums, where participants from all parts of the industry (equipment manufacturers, operators, users, and content, service and applications providers) are represented. This reliance on committee as well as on market processes reinforces the advantages of both forms of standardization. This ensures that the process is faster while at the same time, a high degree of consensus is reached. The configuration of future standardization processes will be very interesting. With the movement described above, official standardization bodies may see their role reduced to solely approving proposals submitted by industry organizations. This could be possible if official bodies maintain a degree of power, which guarantees that they can still decide on the public elements that are typical of standards. This includes elements such as fair competition, fair IPR rules, and ensuring that all industry actors have a say in the development of the standard.

In this paper we have focused on four regions: Japan, China, the US, Europe. In this respect, an interesting development is the shift that is taking place in the regional setting. Japan, the US, and Europe have been the most important regions for the development and diffusion of mobile telecommunication for the first three Gs, but other countries, (such as China and South Korea) have become important players in the $4 \mathrm{G}[55,56]$. Future research could focus on standardization in the Asian region by, e.g., examining the role of South Korea.

Furthermore, we have focused on $1 \mathrm{G}, 2 \mathrm{G}, 3 \mathrm{G}$, and $4 \mathrm{G}$. Currently development of $5 \mathrm{G}$ is under way [57]. Given China's different standardization setting and institutional regime [43], it will be interesting to see how the global standards battle for $5 \mathrm{G}$ will develop and how the role of governments will change. Currently, China's 12th Five Year Plan and MLP [National Medium- and Long-term Plan for the Development of Science and Technology (20062020)], promotes the development of indigenous innovation and the creation of framework conditions for technological development, including standardization. Also, based on the Chinese government's emphasis on 5G and ultra wideband technology development, we can predict that the Chinese government is determined to achieve greater market share and technology breakthroughs in the $5 \mathrm{G}$ era.

Research is often conducted either on standard development in a specific country or on a product with the same characteristics worldwide. In this paper, existing theories are reflected onto different geographic areas. This creates new insights in the theory on standardization processes and thus contributes to the existing literature in this field. Although the investigation is aimed at the mobile telecommunication industry, findings about the influence of factors on standardization in this industry could also be reflected onto other fast moving high tech industries, and thus are applicable in a broader context.

The practical relevance of our study lies in the fact that it compares standardization in a geographic way. For practitioners in the field of mobile telecommunication, and especially those involved in standardization of mobile telecommunication, this paper can help understand differences in standardization processes worldwide, which might be used in daily practice and future standardization efforts.

Open Access This article is distributed under the terms of the Creative Commons Attribution 4.0 International License (http://creativecomm ons.org/licenses/by/4.0/), which permits unrestricted use, distribution, and reproduction in any medium, provided you give appropriate credit to the original author(s) and the source, provide a link to the Creative Commons license, and indicate if changes were made.

\section{References}

1. Kano, S. (2000). Technical innovations, standardization and regional comparison: A case study in mobile communications. Telecommunication Policy, 24, 305-321.

2. Lyytinen, K., \& Fomin, V. V. (2002). Achieving high momentum in the evolution of wireless infrastructures: The battle over $1 \mathrm{G}$ solutions. Telecommunications Policy, 26(3), 149-170.

3. Farrell, J., \& Saloner, G. (1985). Standardization, compatibility, and innovation. The RAND Journal of Economics, 16(1), 70-83.

4. Katz, M. L., \& Shapiro, C. (1985). Network externalities, competition, and compatibility. American Economic Review, 75(3), 424-440.

5. Schilling, M. A. (1998). Technological lockout: An integrative model of the economic and strategic factors driving technology success and failure. Academy of Management Review, 23(2), 267284.

6. Schilling, M. A. (2002). Technology success and failure in winnertake-all markets: The impact of learning orientation, timing, and network externalities. Academy of Management Journal, 45(2), 387-398.

7. Suarez, F. F. (2004). Battles for technological dominance: An integrative framework. Research Policy, 33(2), 271-286.

8. Van de Kaa, G., \& De Vries, H. (2015). Factors for winning format battles: A comparative case study. Technological Forecasting and Social Change, 91(2), 222-235.

9. Van de Kaa, G., Van den Ende, J., De Vries, H. J., \& Van Heck, E. (2011). Factors for winning interface format battles: A review and synthesis of the literature. Technological Forecasting and Social Change, 78(8), 1397-1411.

10. Bekkers, R., Duysters, G., \& Verspagen, B. (2002). Intellectual property rights, strategic technology agreements and market structure: The case of GSM. Research Policy, 31(7), 1141-1161.

11. Funk, J. L. (2003). Standards, dominant designs and preferential acquisition of complementary assets through slight information advantages. Research Policy, 32(8), 1325-1341.

12. Funk, J. L., \& Methe, D. T. (2001). Market- and committee-based mechanisms in the creation and diffusion of global industry standards: The case of mobile communication. Research Policy, 30(4), 589-610.

13. David, P. A., \& Steinmueller, W. E. (1994). Economics of compatibility standards and competition in telecommunication networks. Information Economics and Policy, 6(3-4), 217-241. 
14. Besen, S. M., \& Farrell, J. (1994). Choosing how to compete: Strategies and tactics in standardization. The Journal of Economic Perspectives, 8(2), 117-131.

15. Farrell, J., \& Saloner, G. (1986). Installed base and compatibility: Innovation, product preannouncements, and predation. American Economic Review, 76(5), 940-955.

16. Shapiro, C., \& Varian, H. R. (1999). Information rules, a strategic guide to the network economy. Boston: Harvard Business School Press.

17. Van de Kaa, G., Van den Ende, J., \& De Vries, H. J. (2015). Strategies in network industries: The importance of inter-organisational networks, complementary goods, and commitment. Technology Analysis and Strategic Management, 27(1), 73-86.

18. Van den Ende, J., Van de Kaa, G., Den Uyl, S., \& De Vries, H. (2012). The paradox of standard flexibility: The effects of co-evolution between standard and interorganizational network. Organization Studies, 33(5-6), 705-736.

19. Katz, M. L., \& Shapiro, C. (1986). Technology adoption in the presence of network externalities. The Journal of Political Economy, 94(4), 822-841.

20. Farrell, J., \& Gallini, N. T. (1988). Second-sourcing as a commitment: Monopoly incentives to attract competition. The Quarterly Journal of Economics, 103(4), 673-694.

21. Grindley, P. (1995). Video cassette recorder: The value of cooperation. In P. Grindley (Ed.), Standards, strategy, and policy: Cases and stories. Oxford: Oxford University Press.

22. Den Hartigh, E., Ortt, J. R., Van de Kaa, G., \& Stolwijk, C. C. M. (2016). Platform control during battles for market dominance: The case of Apple versus IBM in the early personal computer industry. Technovation, 48-49, 4-12.

23. David, P. A. (1985). Clio and the economics of QWERTY. The American Economic Review, 75(2), 332-337.

24. Van de Kaa, G., De Vries, H. J., \& Rezaei, J. (2014). Platform selection for complex systems: Building automation systems. Journal of Systems Science and Systems Engineering, 23(4), 415-438.

25. Van de Kaa, G., Rezaei, J., Kamp, L., \& De Winter, A. (2014). Photovoltaic technology selection: A fuzzy MCDM approach. Renewable and Sustainable Energy Reviews, 32, 662-670.

26. Van de Kaa, G., Van Heck, H. W. G. M., De Vries, H. J., Van den Ende, J. C. M., \& Rezaei, J. (2014). Supporting decision-making in technology standards battles based on a fuzzy analytic hierarchy process. IEEE Transactions on Engineering Management, 61(2), 336-348.

27. David, P. A. (1985). Clio and the economics of QWERTY. American Economic Review, 75(2), 332-337.

28. Farrell, J., \& Saloner, G. (1988). Coordination through committees and markets. RAND Journal of Economics, 19(2), 235-252.

29. Katz, M. L., \& Shapiro, C. (1994). Systems competition and network effects. The Journal of Economic Perspectives, 8(2), 93-115.

30. David, P. A., \& Shurmer, M. (1996). Formal standards-setting for global telecommunications and information services. Telecoтmunications Policy, 20(10), 789-815.

31. David, P. A., \& Greenstein, S. (1990). The economics of compatibility standards: An introduction to recent research. Economics of Innovation and New Technologies, 1(1-2), 3-41.

32. Van de Kaa, G., \& De Bruijn, J. A. (2015). Platforms and incentives for consensus building on complex ICT systems: The development of WiFi. Telecommunication Policy, 39, 580-589.

33. Chiesa, V., Manzini, R., \& Toletti, G. (2002). Standard-setting processes: Evidence from two case studies. $R \& D$ Management, 32(5), 431-450.

34. Van de Kaa, G., Den Hartog, F., \& De Vries, H. J. (2009). Mapping standards for home networking. Computer Standards and Interfaces, 31(6), 1175-1181.
35. De Vries, H. J. (1999). Standardization, a business approach to the role of national standardization organizations. Boston: Kluwer Academic Publishers.

36. Egyedi, T. M. (2003). Consortium problem redefined: Negotiating 'Democracy' in the actor network on standardization. International Journal of IT Standards and Standardization Research, 1(2), 2238.

37. Hawkings, R. (1999). The rise of consortia in the information and communication technology industry: Emerging implications for policy. Telecommunications Policy, 23(2), 159-173.

38. European Telecommunication Standards Institute. (2016). http:// www.etsi.org/.

39. International Telecommunications Union. (2016). http://www.itu. int/.

40. Telecommunications Industry Association. (2016). http://www. tiaonline.org/.

41. Backhouse, J., Hsu, C., \& Leiser, S. (2006). Circuits of power in creating de jure standards: Shaping an international information systems security standard. MIS Quarterly, 30(Special Issue), 413438 .

42. Steinfield, C. W., Markus, M. L., \& Wigand, R. T. (2005). Exploring interorganizational systems at the industry level of analysis: Evidence from the US home mortgage industry. Journal of Information Technology, 20, 224-233.

43. Van de Kaa, G., Greeven, M., \& van Puijenbroek, G. (2013). Standards battles in China: Opening up the black-box of the Chinese government. Technology Analysis and Strategic Management, 25(5), 567-581.

44. Gao, J., \& Tan, X. (2015). China's mobile telecom development summary. China's New Telecom, 17(10), 6-7.

45. Li, B. (2010). The operation analysis of TD-SCDMA in China. Telecom Management and Technology, 4, 22-24.

46. Zhang, S. (2008). The government role in standard competition: Case study and theory discussion. Economic Management, Z1, $166-170$

47. Tan, J., \& Lin, R. (2006). TD-SCDMA and the strategy option in telecom standard competition. Management World, 6, 71-84.

48. Sun, Y. (2011). Chinese telecom industry development and 3G application prospect. Jiangsu Business Theory, 5, 65-65.

49. Besen, S. M. (1990). The European Telecommunication Standards Institute: A preliminary analysis. Telecommunications Policy, 14, 521-530.

50. Sadowski, B. M., Dittrich, K., \& Duysters, G. M. (2003). Collaborative strategies in the event of technological discontinuities: The case of Nokia in the mobile telecommunication industry. Small Business Economics, 21, 173-186.

51. Baidupedia. (2016). http://baike.baidu.com/link?url=N4FA2nPUxXaKLf47C7EZes0WMXxrGlvKzQUi2Dsm-cOrFjFuKdII1pjTCv dHdXhractCM7BvSUiJvJqoLCwAK.

52. Wang, J. (2000). Mobile telecom's evolution to 3G. China Wireless Telecommunication, 5, 9-9.

53. Bekkers, R., Bongard, R., \& Nuvolari, A. (2011). An empirical study on the determinants of essential patent claims in compatibility standards. Research Policy, 40(7), 1001-1015.

54. Akyildiz, I. F., Gutierrez-Estevez, D. M., \& Chavarria Reyes, E. (2010). The evolution to 4G cellular systems: LTE-Advanced. Physical Communication, 3, 217-244.

55. Kim, M.-K., Park, M.-C., \& Jeong, D.-H. (2004). The effects of customer satisfaction and switching barrier on customer loyalty in Korean mobile telecommunication services. Telecommunication Policy, 28, 145-159.

56. Jho, W. (2007). Global political economy of technology standardization: A case of the Korean mobile telecommunications market. Telecommunication Policy, 31, 124-138. 
57. Rappaport, T. S., Sun, S., Mayzus, R., Zhao, H., Azar, K. W., Wong, G. N., et al. (2013). Millimeter wave mobile communications for 5G cellular: It will work!. IEEE Access, 1, 335-349.

58. Funk, J. L. (1998). Competition between regional standards and the success and failure of firms in the world-wide mobile communication market. Telecommunication Policy, 22(4/5), 419-441.

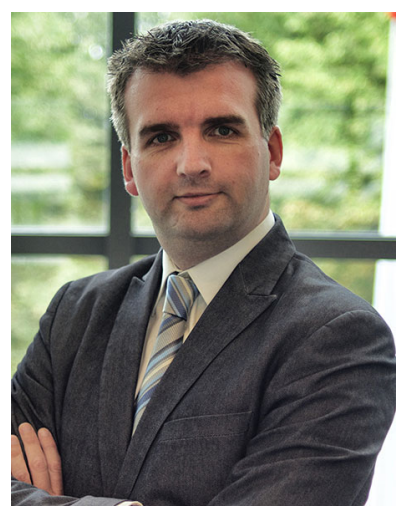

G. van de Kaa is Assistant Professor of Strategy and Innovation at Delft University of Technology. He holds a Ph.D. from Rotterdam School of Management, Erasmus University. His research interests include platform wars for complex systems; (collaboration) strategies for innovation; energy systems; and (responsible) innovation and standardization. $\mathrm{He}$ is the author and coauthor of more than 75 publications. He has published in high ranking international journals including Organization Studies, IEEE Transactions on Engineering Management, Technovation, Technological Forecasting and Social Change, Telecommunications Policy, Technology Analysis \& Strategic Management, Renewable and Sustainable Energy Reviews, Computer Standards \& Interfaces, and Journal of Systems Science and Systems Engineering. He has won several (teaching and research) awards including a best paper award and a best doctoral dissertation award. He teaches courses in the strategic management of technological innovation.

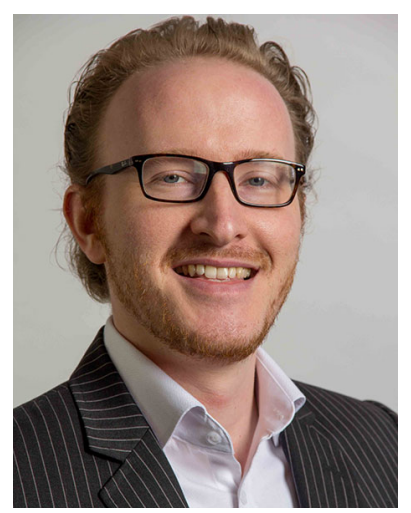

M. J. Greeven (Ph.D., Rotterdam School of Management, Erasmus University) is an associate professor of innovation management at School of Management, Zhejiang University. His research interests include innovation and entrepreneurship and global R\&D in, to, and from China. His work has been published in journals such as the Asia Pacific Journal of Management, European Management Journal and Technology Analysis and Strategic Management. He published a case series on Alibaba and also writes book chapters for publishers like Edward Elgar and Routledge. 